\title{
Microstructure Evolution and Corrosion Performance of AZ31 Magnesium Alloy Sheets
}

\author{
Yang Qingshan ${ }^{1,2}$, Jiang Bin ${ }^{1,2}$, Xiang Qing ${ }^{2}$, Luo Suqin ${ }^{1}, \quad$ Yu Xiaowen ${ }^{2}$, Pan \\ Fusheng $^{1,2}$
}

${ }^{1}$ Chongqing Academy of Science and Technology, Chongqing 401123, China; ${ }^{2}$ National Engineering Research Center for Magnesium Alloys, Chongqing University, Chongqing 400044, China

\begin{abstract}
AZ31 Mg alloy sheets were pre-stretched (PRS) at the angles of $0^{\circ}, 30^{\circ}, 45^{\circ}, 60^{\circ}$ and $90^{\circ}$ between the tensile direction and the extrusion direction at room temperature. Twinning was thus introduced and gradually increased. The microstructure evolutions and corrosion behavior were examined and compared. Results show that the corrosion performance of the twinned Mg alloy sheets is sensitive to the area fraction of twins. Meanwhile, the sheet possessing most area fraction of twins ( $52 \%)$ exhibits the best corrosion resistance. This is attributed to the subdivision of grains by introducing extension twin boundaries. Twinning brings about more grain boundaries that act as a corrosion barrier and thus improve the corrosion resistance.
\end{abstract}

Key words: Mg alloy; microstructure; twinning; corrosion behavior

Magnesium and its alloys are being increasingly applied in electronic and automotive industries due to their high specific strength ${ }^{[1-3]}$. Wrought magnesium alloys have much better mechanical properties compared with the cast ones. However, wrought $\mathrm{Mg}$ alloys generally bring about a strong basal texture during the severe plastic deformation (SPD) process. This is related to their limited number of active deformation systems in hexagonal close-packed (hcp) crystal structure ${ }^{[4,5]}$. Generally, the basal $\langle a\rangle$ slip system of $\mathrm{Mg}$ alloys can be easily activated at room temperature, while the prismatic $\langle a\rangle$ and pyramidal $\langle a+c\rangle$ slip systems can be initiated only if a higher driving force is given or deformed at elevated temperature owing to their high critical resolved shear stress (CRSS) ${ }^{[6,7]}$. Twinning is thus an important supplementary deformation mechanism in these $\mathrm{Mg}$ alloys with the strong basal texture ${ }^{[8,9]}$. Furthermore, the twin has an intensive effect on their deformation mechanism and corrosion behavior. This may enhance or deteriorate the complicity of the mechanical responses in turn. The comprehending of the twins in $\mathrm{Mg}$ alloy sheet has been well known, and concerned extensive researches had been performed ${ }^{[10,11]}$. However, how the twinning affects the corrosion behavior in $\mathrm{Mg}$ alloys is not well understood, yet.

In the present work, the twin effects on the corrosion performance were investigated on AZ31 Mg alloy sheets with the strong basal texture. The twinning behavior was introduced by $8 \%$ pre-stretching during the tensile tests at room temperature. Corrosion resistance of twined AZ31 alloy was examined in $3.5 \mathrm{wt} \% \mathrm{NaCl}$ solution using immersion testing, evolving hydrogen gas measurement and potentiodynamic polarisation measurement. The microstructure evolutions and corrosion performances were characterized and compared.

\section{Experiment}

The starting materials were cut from the hot-extruded AZ31 (Mg-3.3Al-0.9Zn-0.3Mn-0.71Ce, wt \%) alloy sheets with a thickness of $3 \mathrm{~mm}$ (normal direction, ND). Dog-bone tensile samples of $60 \mathrm{~mm}$ in gage length, $12.5 \mathrm{~mm}$ in width and $3 \mathrm{~mm}$ in thickness were machined from the sheets with various directions tilting $0^{\circ}$ (extrusion direction, ED), $30^{\circ}, 45^{\circ}, 60^{\circ}$

$\overline{\text { Received date: July 14, } 2015}$

Foundation item: Chongqing Science and Technology Commission (CSTC2012JJJQ50001, cstc2012ggB50003, CSTC2013jcyjC60001); National Natural Science Foundation of China $(51171212,51474043)$

Corresponding author: Yang Qingshan, Ph. D., Lecturer, Materials Science \& Engineering, Chongqing Academy of Science and Technology, Chongqing 401123, P. R. China, Tel: 0086-23-67398621, E-mail: cquyqs@163.com

Copyright $($ C 2016, Northwest Institute for Nonferrous Metal Research. Published by Elsevier BV. All rights reserved. 
and $90^{\circ}$ (transverse direction, TD). Each tensile specimen was pre-stretched by $8 \%$. Tensile tests were performed at the strain rate of $10^{-3} \mathrm{~s}^{-1}$ using a CMT6305-300KN universal testing machine at room temperature. Square corrosion samples with the dimensions of $10 \mathrm{~mm} \times 10 \mathrm{~mm}$ were cut from the pre-stretched samples.

The results of polarization curves were examined using CHI660D electrochemical workstation with a standard threeelectrode system. The hydrogen evolution rate of the PRS samples was measured in $3.5 \mathrm{wt} \% \mathrm{NaCl}$ solution for $24 \mathrm{~h}$ at room temperature.

The microstructures were examined by optical microscopy $(\mathrm{OM})$. The (0002) pole figure of AZ31 alloy sheet was determined using an X-ray diffractometer (XRD, Rigaku $\mathrm{D} / \mathrm{Max} 2500$ ) with $\mathrm{Cu} \mathrm{K \alpha}$ radiation, a voltage of $40 \mathrm{kV}$ and a current of $100 \mathrm{~mA}$. Morphologies of the corroded surfaces of the specimens were observed by scanning electron microscopy (SEM). The electron backscatter diffraction (EBSD) data were collected using an HKL Chanel 5 System equipped FEI Nova 400 FEG-SEM.

\section{Results and Discussion}

Fig.1a shows the microstructure of the as-received AZ31 alloy sheet (ND-ED plane). The AZ31 sheets are characterized by inhomogeneous microstructure with a few finer equiaxed dynamically recrystallized (DRX) grains of about $20 \mu \mathrm{m}$ embedded in relatively large regions of elongated deformed grains of about $100 \mu \mathrm{m}$. Fig.1b shows (0002) pole figure of the as-received AZ31 alloy sheet. The AZ31 sheets exhibit the basal texture and some $c$-axis orientation of basal planes rotated to TD simultaneously.

In order to introduce the twinning behavior of AZ31 Mg alloy sheets with the strong basal texture, the specimens were all pre-stretched by $8 \%$ during the tensile tests. Fig. 2 shows the optical microstructures of the $8 \%$ PRS samples at room temperature. It is expected that the formation of tension twins is the source of the effects in AZ31sheets with a remarkably basal texture ${ }^{[12]}$. It can be seen that the twins of PRS sheets increase obviously with increasing of angles tilting towards the extrusion direction. It can be calculated that the area fractions of the twins generated during $8 \%$ PRS process are about $5 \%, 16 \%, 24 \% 37 \%$ and $52 \%$. The area fraction of twins in the $90^{\circ}$ PRS sample is the highest.

The as-received AZ31 alloy sheet exhibits the coarse grains with plentiful second phases, as shown in Fig.3a. Here, Fig.3c is the partial enlargement of Fig.3b. The second phase particle can lead to the accumulation of the dislocation tanglement ${ }^{[13]}$. It can also be noted that a great deal of particles exist around the twin boundaries after the fracture in Fig.3b and 3c. Fig.3d and $3 \mathrm{e}$ shows EBSD results of the $90^{\circ}$ PRS sample. It is distinctly seen that grain boundaries in plenty are associated with $\{10 \overline{1} 2\}$ extension twins. These twins are generated during the tensile tests in the different tensile directions with response to the local stress states, which was processed by the deformation of neighboring grains ${ }^{[14]}$. In general, the activity of deformation modes in $\mathrm{Mg}$ alloys are composed of the basal slip along $\langle 11 \overline{2} 0\rangle(\langle a\rangle)$ direction, non-basal slips $(\{10 \overline{1} 0\}-$ prismatic, $\{10 \overline{1} 1\}$-pyramidal and twinning. The plastic deformation mechanism can be assessed by the calculation of the critical resolved shear stress (CRSS). It can be usually received that $\mathrm{CRSS}_{\text {basal }}<\mathrm{CRSS}_{\text {twinning }}<\mathrm{CRSS}_{\text {prismatic }}<\mathrm{CRSS}_{\text {pyramidal }}$ in $\mathrm{Mg}$ and its alloys ${ }^{[7]}$. The resolved shear stress on the basal plane along $c$-axis in the hcp crystal structure increases with increasing of the angles to the extrusion direction. This is due to the strong basal texture associated with some $c$-axis orientations rotating to TD. It is suggested that the basal slip dominates at the initiation of deformation in Mg alloys ${ }^{[15]}$. The twinning is activated to accommodate the deformation as soon as the stress reaches an enough high level ${ }^{[10]}$.

Fig. 4 shows the polarization curves and hydrogen evolutions of the AZ31 sheets. It can be found that there are some important findings regarding the corrosion behavior of wrought AZ31 $\mathrm{Mg}$ alloys and their sensitivity to different variables of the plastic deformation. Corrosion potentials of PRS samples are almost the same as each other with the value of $\sim-1.575 \mathrm{~V}$ for $0^{\circ} \sim 90^{\circ}$ samples, while there are obvious differences in corrosion current density $(2.865,2.835,2.394$, 1.880 and $1.213 \mathrm{~mA} / \mathrm{cm}^{2}$ ), as shown in Fig.4a. The corrosion current density of $0^{\circ}$ sample is the largest, which indicates that it shows the highest electrochemical activity and is most likely to be corroded. There exists a corrosion resistance gradient among PRS samples. The $90^{\circ}$ PRS sample exhibits the best corrosion resistance. Fig. $4 \mathrm{~b}$ shows the hydrogen evolution of the PRS AZ31 sheets as a function of time in $3.5 \mathrm{wt} \% \mathrm{NaCl}$ at

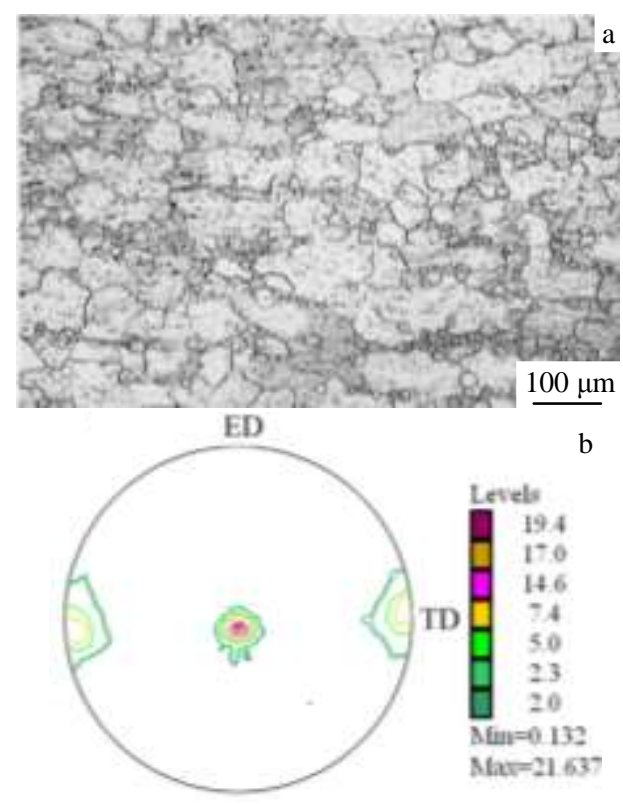

Fig.1 Optical microstructures (a) and (0002) pole figure (b) of the as-received AZ31 alloy sheet 


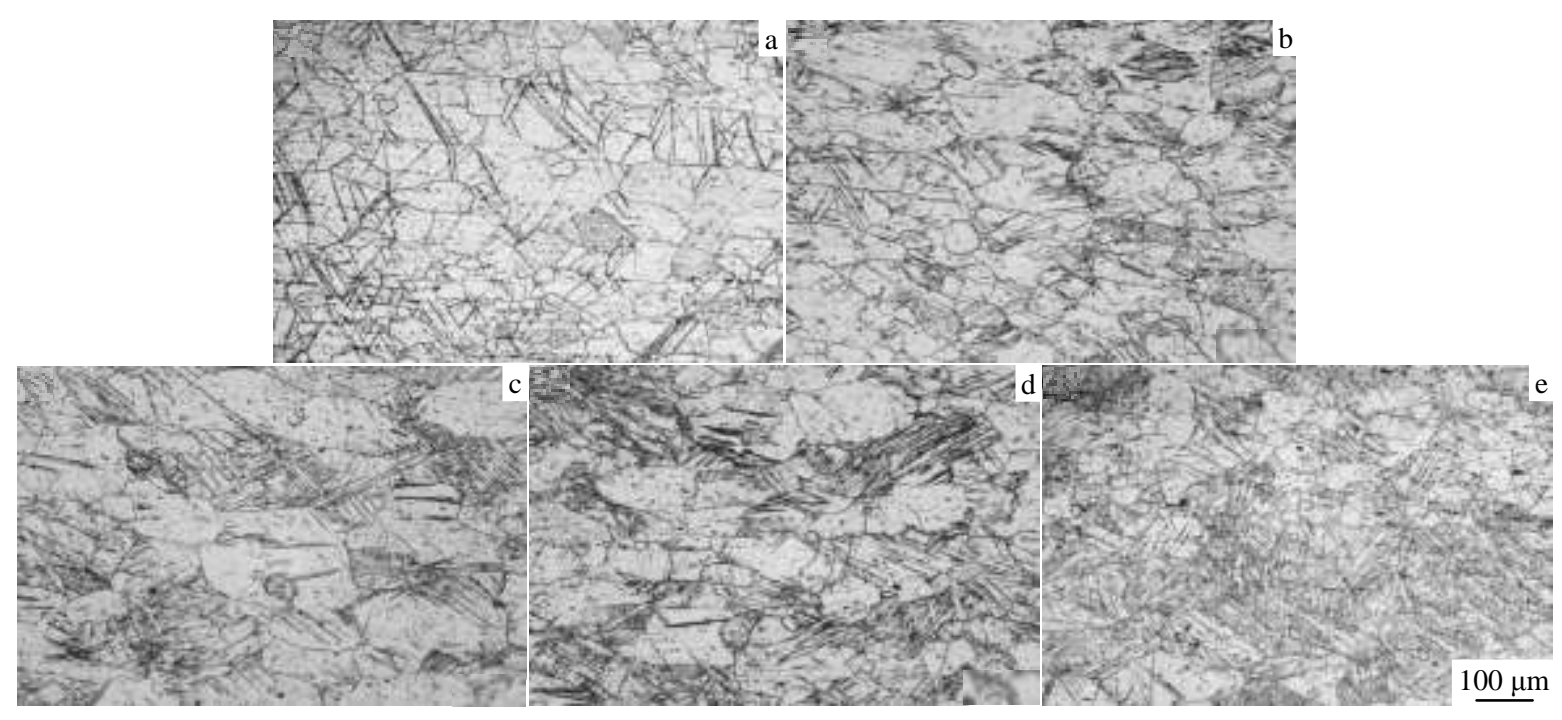

Fig.2 Optical microstructures of PRS samples at different angles: (a) $0^{\circ}$, (b) $30^{\circ}$, (c) $45^{\circ}$, (d) $60^{\circ}$, and (e) $90^{\circ}$

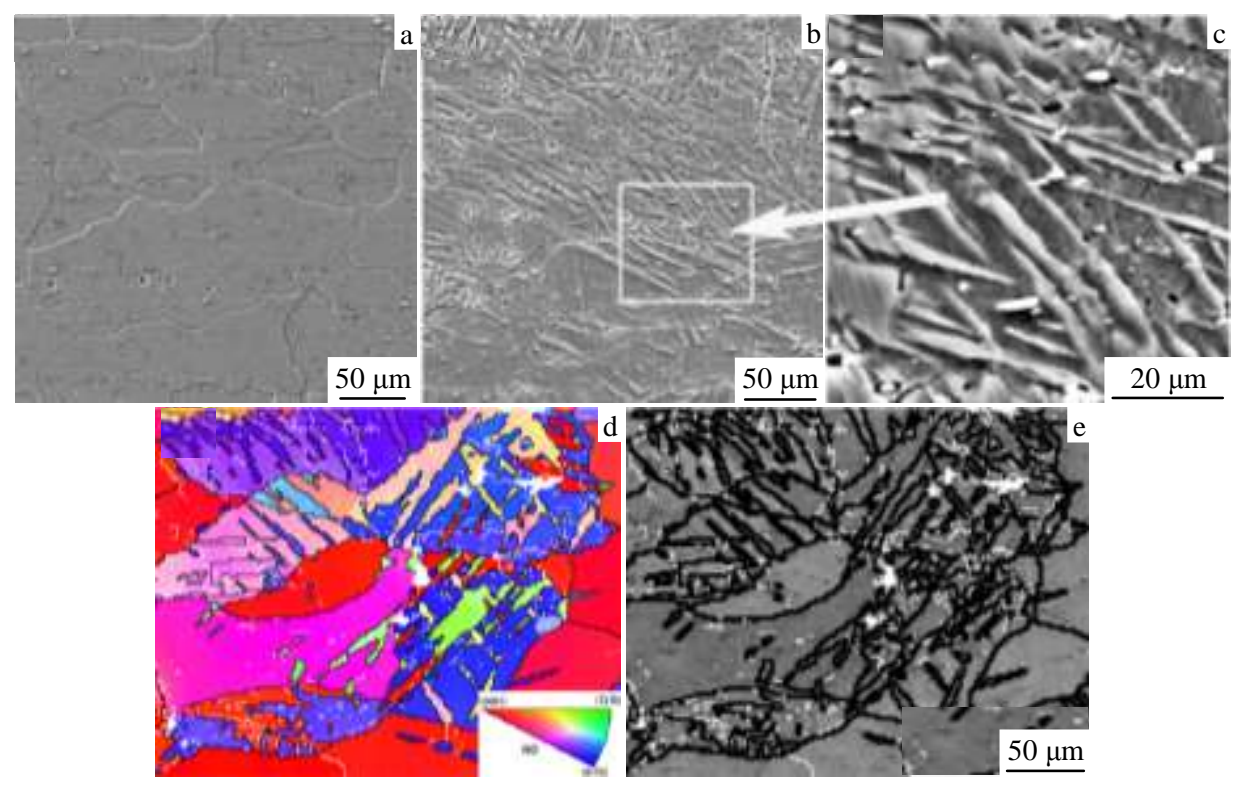

Fig.3 SEM images for as-received AZ31 alloy sheet (a) and $90^{\circ}$ PRS sample (b, c); EBSD maps of the $90^{\circ}$ PRS sample (d, e)

room temperature. The corrosion performance for PRS samples agrees with the results of the polarization curves test. It can be clearly seen that the hydrogen evolution rate of the five AZ31 samples increases in the order: $90^{\circ}$ sample $<60^{\circ}$ sample $<45^{\circ}$ sample $<30^{\circ}$ sample $<0^{\circ}$ sample. This means that the sample with large numbers of twins exhibits the best corrosion resistance. The above comparisons of corrosion potential and current density indicate that the corrosion resistance is obviously improved by twins. The area fraction of twins in $0^{\circ}, 30^{\circ}, 45^{\circ}, 60^{\circ}$ and $90^{\circ}$ samples gradually increases owing to the effect through different angles between $c$-axis and loading direction in the tensile tests. Meanwhile, the twinning assimilates the accumulation of the dislocation density during the deformation in $\mathrm{Mg}$ alloys. Moreover, the subdivision of grains is refined by $\{10 \overline{1} 2\}$ extension twins ${ }^{[16]}$, resulting in more grain boundaries that act as corrosion barriers ${ }^{[17]}$. Grain refinement would bring about the dissolution of impurities in the grain boundaries, less cathodic sites in the AZ31 alloy sheet for cathodic reaction and improved corrosion resistance ${ }^{[18-20]}$. Thus, $90^{\circ}$ PRS sample exhibits much higher corrosion resistance. The above results indicate a clear relationship between the twin and the corrosion performance of PRS samples. Further investigations of the deformed microstructural features are required to clarify the corrosion behavior of the present extruded $\mathrm{Mg}$ alloy sheets. 

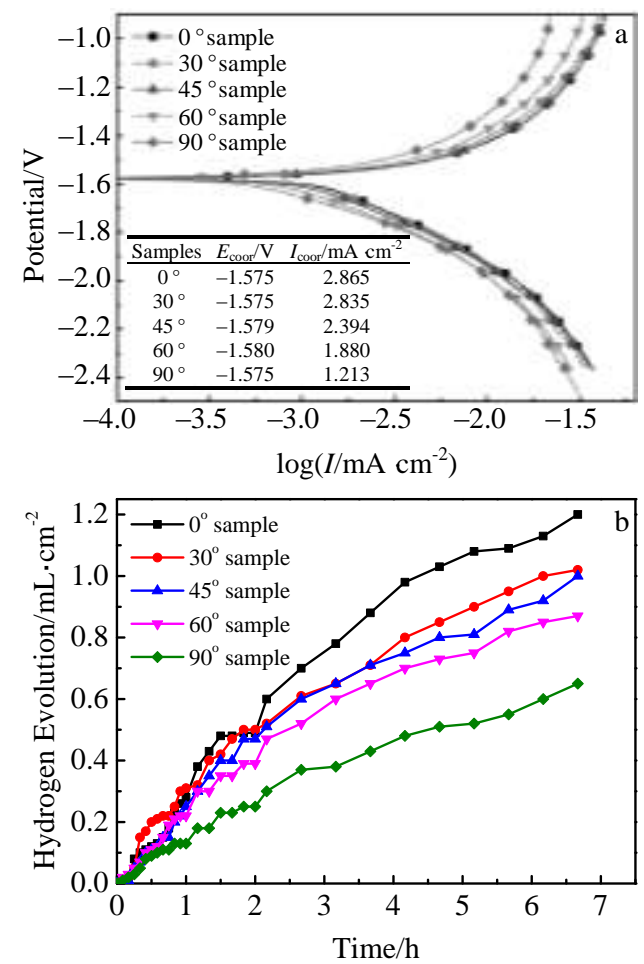

Fig.4 Polarization curves (a) and hydrogen evolutions (b) of the PRS samples

\section{Conclusions}

1) Grains boundaries are increased by $\{10 \overline{1} 2\}$ extension twins in AZ31 alloy sheet.

2) The corrosion resistance is improved by the twin in the twinned microstructure, that is, $90^{\circ}$ PRS sample exhibits the higher corrosion resistance. This is ascribed to the fact that twinning creates more grain boundaries that act as a corrosion barrier.

3) The activity of the deformation twin develops a remarkably positive effect on the corrosion performance of the
$\mathrm{Mg}$ alloy sheets.

\section{References}

1 Seipp S, Wagner M F X, Hockauf K et al. International Journal of Plasticity[J], 2012, 35: 155

2 Luo A A. Journal of Magnesium and Alloys[J], 2013, 1: 2

3 Shi Guoliang, Zhang Dingfei, Zhao Xiabing et al. Rare Metal Materials and Engineering[J], 2013, 42(12): 2447

4 Doiphode R, Narayana Murty S, Prabhu N et al. Journal of Magnesium and Alloys[J], 2013(1): 169

5 Yang Mingbo, Guo Tingzhang, Li Hongliang et al. Rare Metal Materials and Engineering[J], 2013, 42(8): 1541

6 Sankaran A, Vadakke Madam S, Nouri A et al. Scripta Materialia[J], 2012, 66: 725

7 Ulacia I, Dudamell N V, Gálvez F et al. Acta Materialia[J], 2010, 58: 2988

8 Luo J R, Godfrey A, Liu W et al. Acta Materialia[J], 2012, 60: 1986

9 Arab S M, Akbarzadeh A. Journal of Magnesium and Alloys[J], 2013(1): 145

10 Stanford N, Taylor A S, Cizek P et al. Scripta Materialia[J], 2012, 67: 704

11 Sarker D, Chen D L. Scripta Materialia[J], 2012, 67: 165

12 Barnett M R, Davies C H J, Ma X. Scripta Materialia[J], 2005, 52: 627

13 Stanford N, Geng J, Chun YB et al. Acta Materialia[J], 2012, 60: 218

14 Del Valle J A, Carreño F, Ruano O A. Acta Materialia[J], 2006, 54: 4247

15 Wang B, Xin R, Huang G et al. Materials Science and Engineering $A[\mathrm{~J}], 2012,534: 588$

16 Yang Q S, Jiang B, Dai J H et al. Journal of Materials Research[J], 2013, 28: 1148

17 Hamu G B, Eliezer D, Wagner L. Journal of Alloys and Compounds[J], 2009, 468: 222

18 Pu Z, Song G L, Yang S et al. Corrosion Science[J], 2012, 57: 192

19 Song G L, Xu Z. Corrosion Science [J], 2012, 54: 97

20 Deng J F, Huang G S, Zhao Y C et al. Rare Metal Materials and Engineering[J], 2014, 43(2): 316

\title{
AZ31 镁合金板材的微观组织演变及腐蚀行为
}

\author{
杨青山 ${ }^{1,2}$, 蒋 斌 ${ }^{1,2}$, 向 庆 $^{2}$, 罗素琴 ${ }^{1}$, 郁笑雯 ${ }^{2}$, 潘复生 ${ }^{1,2}$ \\ (1. 重庆市科学技术研究院, 重庆 401123) \\ (2. 重庆大学 国家镁合金工程中心, 重庆 400044)
}

\begin{abstract}
摘 要: 在室温下对 $\mathrm{AZ3}$ 镁合金板材分别沿与挤压方向成 $0^{\circ}, 30^{\circ}, 45^{\circ}, 60^{\circ}$ 和 $90^{\circ} 5$ 个方向进行了预拉伸变形, 之后研究了其微观结 构和预变形后板材的腐蚀性能。结果表明, 随着角度的增加, 孪晶数量也随之增加, 孪晶量多的镁合金板材 ( 52\%) 具有较好的抗腐 蚀性。这主要是因为拉伸孪晶引入的更多晶界，使合金的微观结构更为均匀，从而可以抑制腐蚀行为产生。
\end{abstract}

关键词: 镁合金; 微观组织; 孪生; 腐蚀行为

作者简介: 杨青山, 男, 1985 年生, 博士, 讲师, 重庆市科学技术研究院, 重庆 401123, 电话: 023-67308621, E-mail: cquyqs@ 163.com 